\title{
ÍNDICE DE ABERTURA FLORAL E LONGEVIDADE DE HASTES FLORAIS DE LISIANTO [Eustoma grandiflorum(RAF.) Shinn] MANTIDAS EM SOLUÇÕES CONSERVANTES
}

\author{
Daniela Höhn ${ }^{1}$ \\ Lais Perin ${ }^{2}$ \\ Albertina Weith ${ }^{3}$ \\ Dionvera Coelho ${ }^{4}$ \\ Roberta Marins Nogueira Peil ${ }^{5}$ \\ Paulo Roberto Grolli ${ }^{6}$
}

Resumo: O objetivo do trabalho foi avaliar a evolução da abertura floral e a longevidade de hastes de Lisianto (Eustoma grandiflorum (RAF.) Shinn). As hastes foram colhidas de plantas submetidas a diferentes substratos em ambiente protegido, na Universidade Federal de Pelotas - Pelotas, RS. Para a instalação do experimento as hastes foram colhidas, imediatamente suas bases foram imersas em água. Os tratamentos consistiram em: água pura, nitrato de prata (50 mg litro-1), hipoclorito de sódio (25 ml litro-1) e sulfato de alumínio (250 mg litro-1). O delineamento experimental foi inteiramente casualizado composto por quatro tratamentos e seis repetições. A cada dois dias eram feitas as avaliações, durante o período de quatorze dias, verificando-se a evolução da abertura dos botões florais, aparência geral das hastes e longevidade. A solução de sulfato de alumínio e nitrato de prata foram as que proporcionaram a maior abertura dos botões florais e longevidade de quatorze dias das hastes, tornando-se mais eficiente na conservação e pós-colheita de lisianto.

Palavras-chave: Pós-colheita; Durabilidade; Flores de corte.

\footnotetext{
1 Programa de Pós-Graduação em Sistemas de Produção Agrícola Familiar-SPAF/UFPEL, Brasil. E-mail: dani.hohn.sc@gmail.com.

2 Programa de Pós-Graduação em Sistemas de Produção Agrícola Familiar-SPAF/UFPEL, Brasil. E-mail: laliagro@gmail.com.

3 Programa de Pós-Graduação em Sistemas de Produção Agrícola Familiar-SPAF/UFPEL, Brasil. E-mail: albertinawieth@hotmail.com.

4 Programa de Pós-Graduação em Sistemas de Produção Agrícola Familiar-SPAF/UFPEL, Brasil. E-mail: dionveracoelho@gmail.com.

5 Programa de Pós-Graduação em Sistemas de Produção Agrícola Familiar-SPAF/UFPEL, Brasil. E-mail: rpeil@gmail.com.

6 Programa de Pós-Graduação em Sistemas de Produção Agrícola Familiar-SPAF/UFPEL, Brasil. E-mail: prg@gmail.com.
} 